\title{
Ferrocene
}

\section{Róża Hamera}

Department of Organic and Applied Chemistry, University of Łódź, Tamka 12, 94-103 Łódź, Poland

roza.hamera@gmail.com

Published online: 10.07 .2015

DOI: 10.1055/s-0034-1381099; Art ID: st-2015-v0518-v

\section{Introduction}

Ferrocene (1) is an organometallic compound composed of two cyclopentadienyl anions located on both sides of the iron(II) cation. The first report on its synthesis was published in $1951 .^{1}$ It was obtained accidentally by Kealy and Pauson, who actually tried to synthetize fulvene by the reaction of (cyclopentadienyl)magnesium bromide with $\mathrm{FeCl}_{2}$ (Scheme 1). Instead, they isolated an orange coloured solid, which displayed high resistance towards bases and acids. Based on the observed (physico)chemical properties, its structure was determined as a new type of 'sandwich com-
Róża Hamera was born in Lublin, Poland, in 1990. She completed her chemistry studies at the University of Łódź, Poland, in 2014. Currently, she is preparing her PhD thesis under supervision of Professor Grzegorz Mlostoń at the Department of Organic and Applied Chemistry. Her research is focused on the synthesis and reactivity of hetaryl/ferrrocenyl-substituted thioketones.

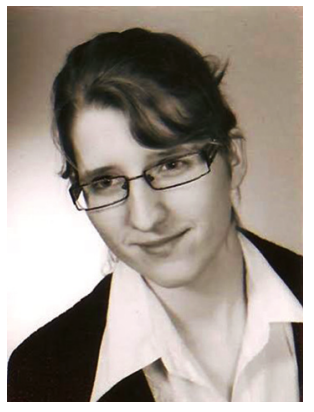

pounds'. ${ }^{2}$ In general, $\mathbf{1}$ is considered a prototype of metallocenes represented by organometallics, including nickelocene, titanocene, and cobaltocene. ${ }^{3}$ In recent years, 1 and its derivatives have attracted great attention as materials with special properties, ligands for asymmetric synthesis, and as important pharmacophores. ${ }^{4}$

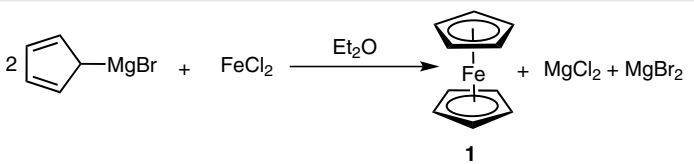

Scheme 1 The first synthesis of ferrocene

Table 1 Use of Ferrocene

Ferrocene (1) was widely applied as a reactive substrate in electrophilic substitution reactions, for example Friedel-Crafts acylation ${ }^{5 a}$ or alkylation. ${ }^{5 \mathrm{~b}}$ Moreover, preparation of (ferrocenyl)diphenylphosphine by a Friedel-Crafts-type reaction of 1 with (chloro)diphenylphosphine was also reported, leading to the formation of a new C-P bond. ${ }^{5 c}$
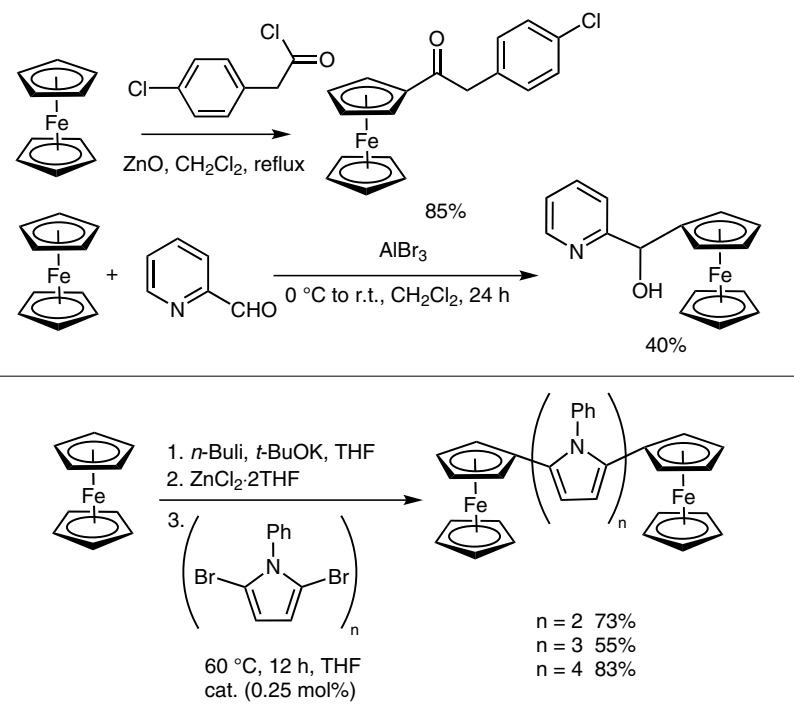

cat. $=\left[\mathrm{Pd}\left(\mathrm{CH}_{2} \mathrm{CMe}_{2} \mathrm{P}\left(t-\mathrm{Bu}_{2}\right)(\mu-\mathrm{Cl})\right]_{2}\right.$

An efficient functionalization of the $\mathrm{N}$-substituted pyrroles by using $\mathbf{1}$ in the Negishi- or Sonogashira-type coupling reactions was reported. ${ }^{6 a}$ In addition, application of the Negishi cross-coupling conditions allowed the preparation of diferrocenyl oligopyrroles in satisfactory to good yield. ${ }^{6 b}$ 
Regioselective introduction of a ferrocenyl substituent into 2phenylindole results in a remarkable increase of cytotoxicity in comparison with the parent compound. ${ }^{7}$ Ferrocenyl-substituted indoles inhibit myeloperoxidase activity and were described as promising anti-inflammatory agents. ${ }^{7}$
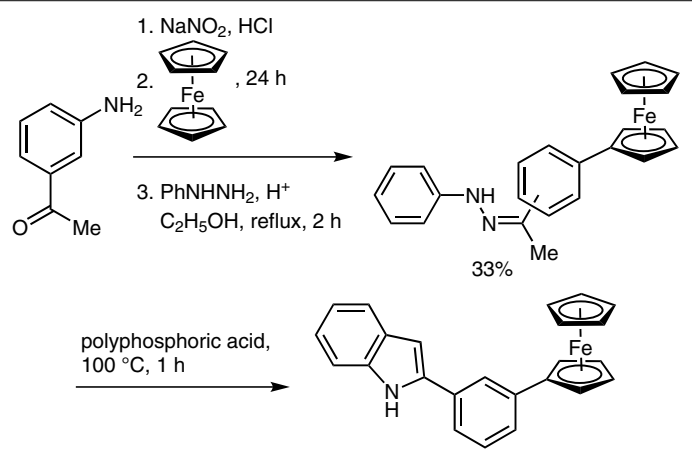

$22 \%$
Triferrocenylsilane was prepared by the 'salt metathesis' reaction between ferrocene-lithium and chlorosilane. In addition, the minor product formed in this reaction was identified as diferrocenyl(3,3dimethylbutyl)silane. The mechanism of the formation of the latter was explained by a cascade of reactions initiated by cleavage and subsequent trapping of a solvent fragment. ${ }^{8}$

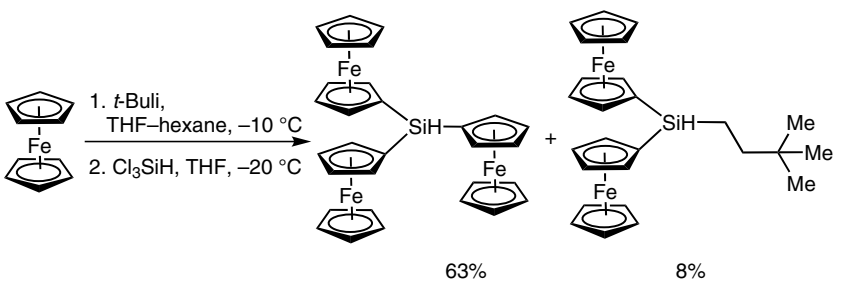

Due to the known electron-transfer ability in redox systems, ferrocenyl-substituted compounds are widely applied in electrochemical studies. For example, ferrocenyl containing mono- and biscarbene chromium $(0)$ complexes were synthetized and examined by means of electrochemical methods. ${ }^{9}$

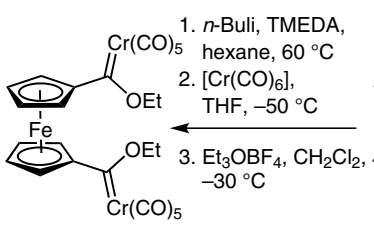

$68 \%$

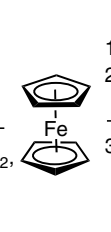

1. $t$-Buli, THF, $-78^{\circ} \mathrm{C}$ 2. $\left[\mathrm{Cr}(\mathrm{CO})_{6}\right]$, 2. $\left[\mathrm{Cr}(\mathrm{CO})_{6}\right]$, $\mathrm{THF},-50^{\circ} \mathrm{C}$ $\mathrm{Et}_{3} \mathrm{OBF}_{4}, \mathrm{CH}_{2} \mathrm{Cl}_{2}$, $-30^{\circ} \mathrm{C}$

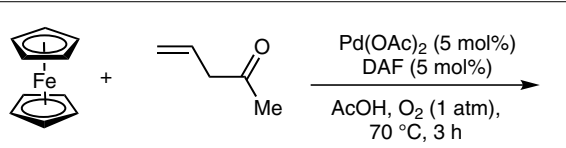

$79 \%$

Ferrocene (1) was successfully applied in the Fujiwara-Moritani reaction with (allenyl)methyl ketone in the presence of a catalytic amount of palladium(II) acetate, yielding alkenyl-substituted ferrocenes. Other, functionalized alkenes were also used in analogous reactions with 1. Remarkably, the obtained products displayed (Z)configuration, exclusively. ${ }^{10}$

\section{References}

(1) Kealy, T. J.; Pauson, P. L. Nature 1951, 168, 1039.

(2) Wilkinson, G.; Rosenblum, M.; Whiting, M. C.; Woodward, R. B. J. Am. Chem. Soc. 1952, 74, 2125.

(3) Wilkinson, G.; Pauson, P. L.; Cotton, F. A. J. Am. Chem.Soc. 1953, $76,1970$.

(4) Ferrocenes: Ligands Materials and Biomolecules; Štěpnička, P. J., Ed.; Wiley \& Sons Ltd: Chichester, UK, 2008.

(5) (a) Anjo, C.; Figueiredo, J. A.; Ismael, M. I.; Cabrita, I.; Fernandes, A. C. J. Organometallic Chem. 2014, 760, 19. (b) Harikrishnan, A.; Selvakumar, J.; Gnanamani, E.; Bhattacharya, S.; Ramanathan, C. R. New J. Chem. 2013, 37, 563. (c) Fourie, E.; Janse van Rensburg, J. M.; Swarts, J. C. J. Organometallic Chem. 2014, 754, 80.
(6) (a) Korb, M.; Pfaff, U.; Hildebrandt, A.; Rüffer, T.; Lang, H. Eur. J. Inorg. Chem. 2014, 1051. (b) Pfaff, U.; Lang, H.; Hildebrandt, A.; Schaarschmidt, D.; Rüffer, T.; Low, P. J. Organometallics 2013, $32,6106$.

(7) Radulović, N. S.; Zlatković, D. B.; Mitić, K. V.; Randjelović, P. J.; Stojanović, N. M. Polyhedron 2014, 80, 134.

(8) Bruña, S.; Perles, J.; Nieto, D.; Ma González-Vadillo, A.; Cuadrado, I. J. Organometallic Chem. 2014, 751, 769.

(9) Van der Westhuizen, B.; Swarts, P. J.; Strydom, I.; Liles, D. C.; Fernández, I.; Swarts, J. C.; Bezuidenhout, D. I. Dalton Trans. 2013, 42, 5367.

(10) Piotrowicz, M.; Zakrzewski, J. Organometallics 2013, 32, 5709. 